\title{
Ventilator associated complications: observing implications of a new surveillance paradigm
}

\author{
M Yuan, M Aaland, N Parekh* \\ From ESICM LIVES 2015 \\ Berlin, Germany. 3-7 October 2015
}

\section{Introduction}

Surveillance for Ventilator Associated Pneumonia (VAP) is problematic. The CDC published a new surveillance framework [1] with two main goals.

- Broaden focus of surveillance beyond VAP to include other common ventilator-associated complications (VACs).

- Produce objective surveillance definitions using quantitative data based on changes in ventilator settings.

It introduces a hierarchy of surveillance targets:

1. Ventilator associated complications (VAC). Includes both pulmonary and non pulmonary complications.

2. Infection related (IVAC) complications with an infective component.

\section{Objectives}

To gain an impression of rates of ventilator acquired complications using the new CDC criteria and impact on antibiotic prescription.

\section{Methods}

- Inclusion Criteria: All consecutive patients intubated for at least 48 hours

- Exclusion Criteria: All elective post-cardiac surgery

- Follow Up: Until extubation or death

- Three random period of data collection

- In the first round data on 40 patients were captured

- Four months later in a second round a total of 18 patients were recruited.

\section{Results}

First round (Figure 1) on 23 patients shows VAC incidence of 7/23 (30.4\%). In VAC group, 4 (17\%) met IVAC criteria as possible pneumonia. Second round (Figure 2) enrolled 17 patients and shows VAC rate of $1 / 17(11 \%)$ and that one case was possible pneumonia. Third round (Figure 3) enrolled 18 patients and shows a VAC rate of $4 / 18(22 \%)$. In VAC group, 1 developed IVAC $(6 \%)$ as possible pneumonia. Thus VAC rate var-

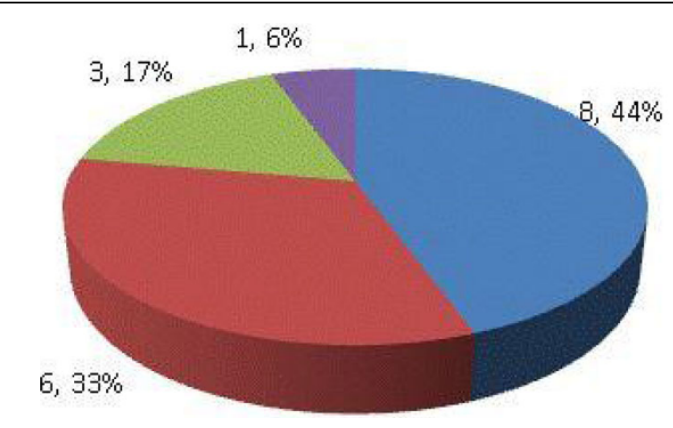

No evidence of IVAC,

Antibiotics prescribed

- No VAC/VAC, antibiotics

not prescribed

IVAC, On appropriate

antibiotics

- VAC only, On antibiotics

Figure 1

Queen Elizabeth Hospital Birmingham, Anaesthesia and Critical Care,

Birmingham, United Kingdom

(c) 2015 Yuan et al.; This is an Open Access article distributed under the terms of the Creative Commons Attribution License (http:// creativecommons.org/licenses/by/4.0), which permits unrestricted use, distribution, and reproduction in any medium, provided the original work is properly cited. 


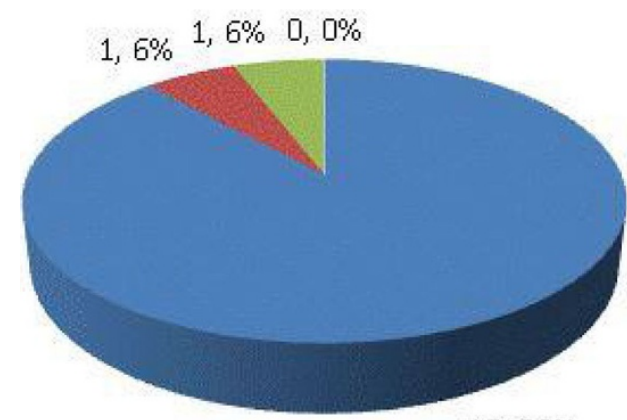

$15,88 \%$
No evidence of IVAC,

Antibiotics prescribed

a No $\mathrm{VAC/VAC}$, Antibiotics

not prescribed

- VAC, On appropriate antibiotics

VAC only, On antibiotics

Figure 2

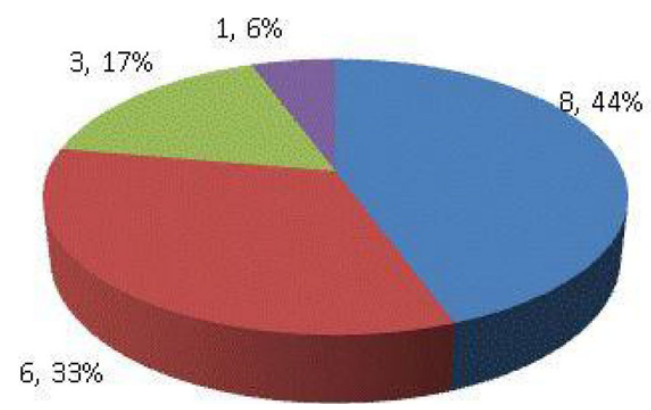

no evidence of IVAC,

Antibiotics prescribed

- No VAC/VAC, antibiotics

not prescribed

IVAC, On appropriate

antibiotics

- VAC only, On antibiotics

Figure 3

ied from $11-30 \%$ but IVAC due to pneumonia ranged from $5-17 \%$.

\section{Conclusions}

- New CDC definition for VAC are easy to apply and removal of subjective criteria must be welcomed

- New definitions of IVAC allows clinicians to increase antibiotics free rate by $18-37 \%$ relatively

- In these 3 cohorts, several patients were treated with antibiotics despite no evidence to classify as IVAC. This can only be attributed to subjective decision and interpretation of chest $\mathrm{x}$-ray

- The commonest indication for antibiotic prescription was non-pulmonary.

- Patients in possible pneumonia group on microbiology did not meet other IVAC criteria, highlighting issue of colonisation being treated with antibiotics

- IVAC metric thus has potential to identify outlier antibiotic prescribers

- Objective criteria to classify patients into VAC and IVAC has potential for automation in order to monitor the incidence of VAC, adding value to clinical dash board

\section{Reference}

1. Klompas M: NEJM 2013, 368;16:1472-75.

doi:10.1186/2197-425X-3-S1-A941

Cite this article as: Yuan et al:: Ventilator associated complications:

observing implications of a new surveillance paradigm. Intensive Care Medicine Experimental 2015 3(Suppl 1):A941.

\section{Submit your manuscript to a SpringerOpen ${ }^{\circ}$ journal and benefit from:}

- Convenient online submission

- Rigorous peer review

- Immediate publication on acceptance

- Open access: articles freely available online

- High visibility within the field

- Retaining the copyright to your article

Submit your next manuscript at $>$ springeropen.com 